\title{
2-Amino-1-methyl-6-phenylimidazo[4,5-b]pyridine (PhIP) formation and fate: An example of the coordinate contribution of lipid oxidation and Maillard reaction to the production and elimination of processing- related food toxicants
}

\author{
${ }_{5}$ Rosario Zamora and Francisco J. Hidalgo $*^{a}$ \\ Received (in $X X X, X X X)$ Xth $X X X X X X X X X 20 X X$, Accepted Xth $X X X X X X X X X 20 X X$ \\ DOI: $10.1039 / b 000000 x$
}

2-Amino-1-methyl-6-phenylimidazo[4,5-b]pyridine ( $\mathrm{PhIP})$ is produced by reaction of phenylacetaldehyde, the Strecker aldehyde of phenylalanine, with creati(ni)ne in the presence of 10 formaldehyde and ammonia, which are formed in situ. Traditionally, the carbonyls compounds required for the formation of PhIP ring were considered to be produced as a consequence of Maillard reaction between phenylalanine and carbohydrates. This review collects all recent evidences suggesting that lipids can also contribute to produce the Strecker degradation of phenylalanine and the formation of formaldehyde analogously to carbohydrates. Furthermore, lipid-derived reactive carbonyls not only 15 contribute to PhIP formation but they can also be involved in PhIP fate observed in the presence of oxidized oils. This role has not been yet investigated for carbohydrate-derived reactive carbonyls but it might be hypothesised to take place because of the decrease of PhIP observed when excess of monosacharides is employed to study PhIP formation. All these results suggest that carbohydrates and lipids can contribute simultaneously to PhIP formation and fate. This is another example of the 20 simultaneous contribution of both lipids and carbohydrates to the carbonyl chemistry that takes place in foods upon processing and/or storage. Furthermore, many of these conclusions can also be extended to the formation of other aminoimidazoazarenes with structure of imidazopyridine.

\section{Introduction}

Thermal processing has numerous beneficial consequences for ${ }_{25}$ foods, including enhancement of nutritional quality, improved digestibility and bioavailability of nutrients, prolongation of shelf-life, better palatability, taste, texture, flavour, and functional properties, release of bioactive components, generation of beneficial compounds with antioxidant and antimicrobial 30 properties, destruction of anti-nutritional substances, and inactivation of food-borne pathogens. ${ }^{1}$ However, it also produces a loss of certain nutrients and the formation of potentially mutagenic and carcinogenic molecules. ${ }^{2}$ To this respect, formation of acrylamide, ${ }^{3}$ furan, ${ }^{4}$ acrolein, ${ }^{5}$ or heterocyclic 35 aromatic amines, ${ }^{6}$ among others, has received a considerable attention in recent years. In particular, heterocyclic aromatic amines have been related to the increased cancer risk associated with the consumption of cooked proteinaceous food products. ${ }^{7}$

Heterocyclic aromatic amines are a complex mixture of 40 compounds formed at ppb levels in muscle foods cooked at high temperature. ${ }^{8}$ They are characterized for having a planar, multiring aromatic structure with one or more nitrogen atoms in their ring system and, usually, an exocyclic amino group, although there are also some few exceptions. ${ }^{9}$ Chemical structures of the
45 main heterocyclic aromatic amines isolated to present are collected in Fig. 1.

Heterocyclic aromatic amines can be classified in two groups: aminoimidazoazarenes, which are usually formed at temperatures typical of cooking/frying $\left(\sim 200{ }^{\circ} \mathrm{C}\right)$, and pyrolitic heterocyclic 50 aromatic amines, which are formed by pyrolysis of amino acids and proteins at temperatures higher than $250^{\circ} \mathrm{C}$. Among them, and based on evidences from animal experiments, the International Agency for Research on Cancer (IARC) has classified three of these amines [2-amino-3,455 dimethylimidazo[4,5-f]quinoline (MeIQ), 2-amino-3,8dimethylimidazo[4,5-f]quinoxaline (8-MeIQx), and 2-amino-1methyl-6-phenylimidazo[4,5-b]pyridine (PhIP)] in the class 2B as possible human carcinogens, and one of them [2-amino-3methylimidazo[4,5-f]quinoline (IQ)] in the class $2 \mathrm{~A}$ as a probable ${ }_{60}$ human carcinogen. ${ }^{10}$ These four amines have also been listed by the National Toxicology Program (NTP) in its $11^{\text {th }}$ Report on Carcinogens (RoC) as reasonably anticipated to be human carcinogens. ${ }^{11}$ All these four compounds are aminoimidazoazarenes.

65 Although more than 20 aminoimidazoazarenes have been isolated and characterized to present, only three basic skeletons are repeated in the identified compounds: imidazopyridine, imidazoquinoline, and imidazoquinoxaline. This similarity 


\section{AMINOIMIDAZOAZARENES}

imidazopyridine derivatives<smiles>[R]c1cc2c(nc1[R])nc(N)n2C</smiles>

DMIP: $\mathrm{R}_{1}=\mathrm{H}, \mathrm{R}_{2}=\mathrm{CH}_{3}$ 1,5,6-TMIP: $\mathrm{R}_{1}=\mathrm{R}_{2}=\mathrm{CH}_{3}$ PhIP: $\mathrm{R}_{1}=\mathrm{H}, \mathrm{R}_{2}=$ phenyl

4'-OH-PhIP: $\mathrm{R}_{1}=\mathrm{H}, \mathrm{R}_{2}=4$ '- $\mathrm{OH}$-phenyl<smiles>Cc1cc2nc3nc(N)n(C)c3cc2o1</smiles>

IFP<smiles>[R]c1cc2ncccc2c2nc(N)n(C)c12</smiles>

$I Q: R=H$

MelQ: $\mathrm{R}=\mathrm{CH}_{3}$<smiles>[R]c1nc2cc(Br)c3c(nc(N)n3C)c2nc1[R]</smiles>

$I Q x: R_{1}=R_{2}=R_{3}=H$

4-MelQx: $\mathrm{R}_{1}=\mathrm{CH}_{3}, \mathrm{R}_{2}=\mathrm{R}_{3}=\mathrm{H}$

7-MelQx: $\mathrm{R}_{1}=\mathrm{R}_{3}=\mathrm{H} ; \mathrm{R}_{2}=\mathrm{CH}_{3}$,

8-MelQx: $\mathrm{R}_{1}=\mathrm{R}_{2}=\mathrm{H} ; \mathrm{R}_{3}=\mathrm{CH}_{3}$,

4,8-DiMelQx: $\mathrm{R}_{1}=\mathrm{R}_{3}=\mathrm{CH}_{3}, \mathrm{R}_{2}=\mathrm{H}$

7,8-DiMelQx: $\mathrm{R}_{1}=\mathrm{H} ; \mathrm{R}_{2}=\mathrm{R}_{3}=\mathrm{CH}_{3}$,

4,7,8-TriMelQx: $\mathrm{R}_{1}=\mathrm{R}_{2}=\mathrm{R}_{3}=\mathrm{CH}_{3}$

4- $\mathrm{CH}_{2} \mathrm{OH}-8-\mathrm{MelQx}: \mathrm{R}_{1}=\mathrm{CH}_{2} \mathrm{OH}, \mathrm{R}_{2}=\mathrm{H}, \mathrm{R}_{3}=\mathrm{CH}_{3}$<smiles>[R]c1nc2cc3nc(N)n(C)c3c([R3])c2nc1[R]</smiles>

$\operatorname{lgQx}: \mathrm{R}_{1}=\mathrm{R}_{2}=\mathrm{R}_{3}=\mathrm{H}$

6-MelgQx: $\mathrm{R}_{1}=\mathrm{CH}_{3}, \mathrm{R}_{2}=\mathrm{R}_{3}=\mathrm{H}$

7-MelgQx: $\mathrm{R}_{1}=\mathrm{R}_{3}=\mathrm{H}, \mathrm{R}_{2}=\mathrm{CH}_{3}$

6,7-DiMelgQx: $\mathrm{R}_{1}=\mathrm{R}_{2}=\mathrm{CH}_{3}, \mathrm{R}_{3}=\mathrm{H}$

7,9-DiMelgQx: $\mathrm{R}_{1}=\mathrm{H}, \mathrm{R}_{2}=\mathrm{R}_{3}=\mathrm{CH}_{3}$

PYROLYTIC HETEROCYCLIC AROMATIC AMINES

phenylpyridine derivatives<smiles>Nc1ccc(-c2ccccc2)cn1</smiles>

Phe-P-1 $\alpha$-carbolines<smiles>[R]c1cc2c(nc1N)[nH]c1ccccc12</smiles>

$A \alpha C: R_{1}=H$ $\mathrm{MeA} \alpha \mathrm{C}: \mathrm{R}_{1}=\mathrm{CH}_{3}$

\section{$\beta$-carbolines}

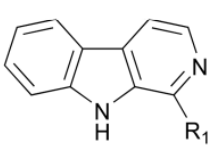

Norharman: $\mathrm{R}_{1}=\mathrm{H}$

Harman: $\mathrm{R}_{1}=\mathrm{CH}_{3}$

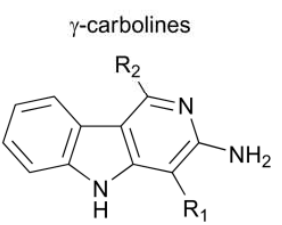

Trp-P-1: $\mathrm{R}_{1}=\mathrm{R}_{2}=\mathrm{CH}_{3}$

Trp-P-2: $\mathrm{R}_{1}=\mathrm{H}, \mathrm{R}_{2}=\mathrm{CH}_{3}$

other derivatives<smiles>[R]c1cccn2c1nc1ccc(N)nc12</smiles>

Glu-P-1: $\mathrm{R}=\mathrm{CH}_{3}$

Glu-P-2: $R=H$<smiles>Cc1nc(N)c2c3c1c1cccnc1n3CN=C2</smiles>

Orn-P-1<smiles>CNc1nc2c(N)c3c(cc2n1C)C(=O)N(C)C3=O</smiles>

Cre-P-1

Fig. 1 Chemical structures for main heterocyclic aromatic amines. 


\section{Cite this: DOI: 10.1039/c0xx00000x}

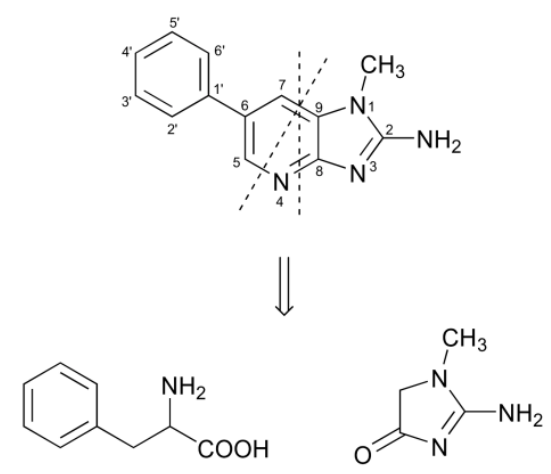

Scheme 1 Retrosynthetic analysis of PhIP

among all these compounds suggests that all of them are produced from a limited number of reactants through a reduced 5 number of formation pathways. In fact, these compounds have been traditionally considered to be the result of complex reactions that involve creati(ni)ne, free amino acids, and carbohydrates through the Maillard reaction. However, a recent study has pointed out that some of these compounds can also be formed as 10 a consequence of the carbonyl chemistry initiated by lipid oxidation, ${ }^{12}$ and previous studies also showed contradictory results on the influence of fats in formation and fate of heterocyclic aromatic amines. ${ }^{13}$

Maillard reaction and lipid oxidation are not two independent 15 processes. In fact, lipid oxidation products influence Maillard pathway and vice versa, and there are common intermediates and analogous polymerization mechanisms in both routes conducting to food browning. ${ }^{14}$ The objective of this review is to collect the scattered existing information suggesting that this coordinate 20 contribution of both lipid oxidation and Maillard reaction to food browning is also playing a role in the formation and fate of heterocyclic aromatic amines. This review will be mostly focused on PhIP because it is the heterocyclic aromatic amine that has been mostly studied in this sense.

\section{2. PhIP: a product of carbonyl chemistry in foods}

Among the different aminoimidazoazarenes produced under usual cooking conditions, PhIP is generally one of the heterocyclic aromatic amines produced to a highest extent in addition to 230 amino-1,7-dimethylimidazo[4,5-g]quinoxaline (7-MeIgQx), 8MeIgQx, and 2-amino-1,7,9-trymethylimidazo[4,5-g]quinoxaline (7,9-DiMeIgQx). ${ }^{13,15,16} \mathrm{PhIP}$ is typically found in foods at amounts up to $35 \mathrm{ng} / \mathrm{g},{ }^{17}$ but there are reports of higher levels, especially in fried and barbecued chicken. ${ }^{18}$

35 The mechanism by which PhIP is produced has been the objective of different studies but it has not been fully elucidated until very recently. ${ }^{19}$ First studies demonstrated that PhIP is produced by reaction of phenylalanine with creati(ni)ne. ${ }^{16,20-23}$
The atoms of both reactants were easily located on the PhIP 40 molecule by using isotope labelling. ${ }^{23}$ Thus, phenylalanine is responsible for the phenyl ring and carbons 5,6 , and 7 of the pyridine ring in PhIP (Scheme 1). In addition, creatinine is incorporated almost intact to the $\mathrm{PhIP}$ molecule and is responsible for the imidazole ring. This last part is common for 45 all aminoimidazoazarenes where the synthon creatinine can be easily recognized (Fig. 1). Although phenylalanine has 9 carbons and 9 carbons come from the amino acid in PhIP, phenylalanine cannot be incorporated directly to PhIP molecule because the phenyl ring is attached to one end of the alkyl chain in ${ }_{50}$ phenylalanine, and the phenyl ring is attached to the centre of the three carbons of the pyridine ring in PhIP that initially belonged to phenylalanine. In addition, and by means of isotopic labelling, the no incorporation of the carboxylic carbon of phenylalanine to PhIP was also demonstrated. ${ }^{23}$ This fact suggested that ${ }_{55}$ phenylalanine suffered a degradation previously to form part of PhIP. The formed compound, which was an intermediate in the reaction, was found to be phenylacetaldehyde. ${ }^{16}$ Therefore the first step of the formation of PhIP is the Strecker degradation of phenylalanine to produce phenylacetaldehyde (Scheme 2), a step 60 that does not need the presence of creati(ni)ne but is facilitated in the presence of reactive carbonyl compounds derived from carbohydrates, ${ }^{24,25}$ lipids, ${ }^{26}$ amino acids, ${ }^{27}$ or polyphenols ${ }^{28}$ (see below).

Once phenylacetaldehyde is formed, the reaction between ${ }_{65}$ phenylacetaldehyde and creati(ni)ne is produced to form in a first step 2-amino-5-(1-hydroxy-2-phenylethyl)-1-methyl-1Himidazol-4(5H)-one and then, after dehydration, 2-amino-1methyl-5-(2-phenylethylidene)- $1 H$-imidazol-4(5H)-one. ${ }^{16}$ This last compound has already the basic structure of the PhIP, but it 70 still needs the finishing of the pyridine ring with the inclusion of one carbon and one nitrogen atoms.

The origin of both atoms has been the objective of different studies. Thus, the nitrogen seemed to come from the thermal decomposition of both phenylalanine and creati(ni)ne, which is 75 known to produce ammonia. ${ }^{29}$ In addition, Murkovic et al. ${ }^{23}$ found that the origin of the additional carbon was the carbon 2 of phenylalanine by using isotope labelling. More recently, Zamora et al. ${ }^{19}$ found that thermal degradation of phenylacetaldehyde produced formaldehyde, and this is the way in which the last 80 carbon is incorporated to complete PhIP molecule. Formaldehyde has been suggested to be produced as shown in Scheme 2, at least to a certain extent. ${ }^{19}$ Upon heating, a small amount of phenylacetaldehyde suffered a disproportionation reaction to produce phenylacetic acid and phenylethanol (both products were 85 detected in the reaction mixture of heated phenylacetaldehyde). The later dehydration of the alcohol, the oxidation of the produced olefin, and, finally, its breakage would be the origin of formaldehyde. Therefore, the origin of formaldehyde would be the carbon 2 of phenylalanine, which is in agreement with the 90 labelling experiments. ${ }^{23}$

Once ammonia and formaldehyde have been formed, the $\mathrm{PhIP}$ 


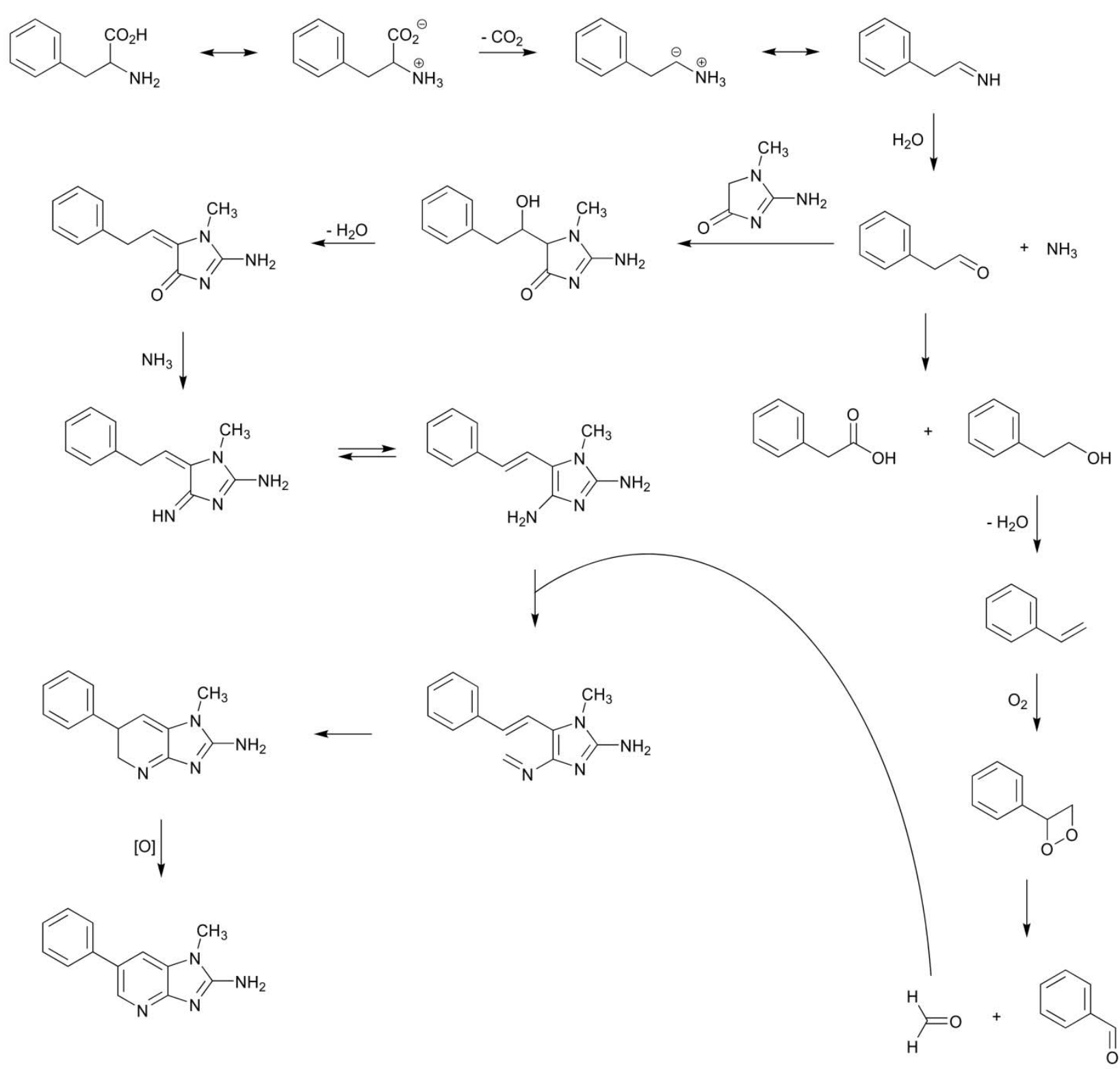

Scheme 2 PhIP formation pathway

molecule may be completed as suggested in Scheme 2. The reaction between the condensation product of phenylacetaldehyde and creatinine with ammonia would produce the corresponding 5 imine, which later would evolve the amine by tautomerisation. This amine would then react with formaldehyde to produce a new imine, which after electronic rearrangement and oxidation, would be the origin of PhIP.

Therefore, PhIP is produced in four steps:

101 Formation of the Strecker aldehyde from the parent amino acid.

2 Reaction of the phenylacetaldehyde with creati(ni)ne to produce the aldol condensed product.

3 Formation of formaldehyde and ammonia from phenylacetaldehyde, phenylalanine or creati(ni)ne.

4 Final assembly of the molecule by incorporating formaldehyde and ammonia.

Obviously, although steps 1,2 , and 4 have to take place sequentially, step 3 can take place simultaneously to steps 1 or 2 . ${ }_{20}$ Furthermore, in complex food products, formaldehyde and ammonia can have other origins different to phenylacetaldehyde, phenylalanine, or creati(ni)ne.

This four-step mechanism described for PhIP might be general 
<smiles>Cn1c(N)nc2ncc(-c3ccc(O)cc3)cc21</smiles>

4'-OH-PhIP

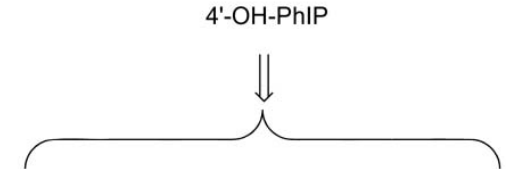<smiles>CN1CC(=O)N=C1N</smiles><smiles>C=C(C)CCC(C)C=CC(N)=O</smiles><smiles>C=C(N)CC(C)CCC(C)C</smiles>

Scheme 3 Retrosynthetic analyses of 2-amino-1-methyl-6-(4hydroxtphenyl)imidazol[4,5-b]pyridine (4'-OH-PhIP), 2-amino-1,6dimethylimidazo[4,5-b]pyridine (DIMP), and 2-amino-1,5,6trimethylimidazo[4,5-b]pyridine (1,5,6-TIMP).

5 for the different imidazopyridine derivatives identified to present. Thus, the formation of 2-amino-1-methyl-6-(4hydroxyphenyl)imidazo[4,5-b]pyridine (4'-OH-PhIP) should be produced analogously to $\mathrm{PhIP}$ with the only difference of the change of phenylacetaldehyde by the Strecker aldehyde of 10 tyrosine 2-(4-hydroxyphenyl)acetaldehyde (Scheme 3).

The formation pathway of 2-amino-1,6-dimethylimidazo[4,5b]pyridine (DIMP) can also be hypothesized to be produced analogously by starting from propanal in the place of phenylacetaldehyde (Scheme 3). Propanal is not a Strecker 15 aldehyde derived from amino acids, but it is a major oxidation product of $n 3$ fatty acids. ${ }^{30}$

Analogously, 2-amino-1,5,6-trimethylimidazo[4,5-b]pyridine (1,5,6-TMIP) can be hypothesised to be produced analogously to DIMP but with acetaldehyde in the place of formaldehyde to

20 close of the pyridine ring (Scheme 3). Acetaldehyde is a common component in many foods where it is formed from carbohydrates, lipids or phenols, among other food components. ${ }^{31}$

An analogous pathway can also be proposed for the formation of 2-amino-1,6-dimethylfuro[3,2-e]imidazo[4,5-b]pyridine (IFP) 25 by reaction of 5-methylfurfural, creati(ni)ne and ammonia (Scheme 4). In this case, steps 1 and 3 are fused together with the formation of 5-methylfurfural. This compound has been shown to be both a byproduct of the Maillard reaction ${ }^{32}$ and a product of lipid oxidation. ${ }^{33}$ The aldol reaction between 5-methylfurfural 30 and creatinine would produce the corresponding adduct that can later be dehydrated. The carbonyl group of the initial creatinine would then react with ammonia to produce the corresponding imine, which lately would suffer an electronic rearrangement and oxidation to produce IFP.

35 Although it is not classified under imidazopyridine derivatives, an analogous formation mechanism can also be hypothesized for 2-amino-1-methylimidazo[4,5-b]quinoline (IQ[4,5-b]), the linear tricyclic isomer of the probable human carcinogen IQ. The reaction pathway would be analogous to that of IFP but the initial 40 aldehyde would be benzaldehyde, also a common minor food component. ${ }^{34}$ The reaction pathway is shown in Scheme 5. The reaction of benzaldehyde and creatinine would produce the corresponding aldol in a first step and then the dehydrated adduct. The reaction of this compound with ammonia followed by an 45 electronic rearrangement and oxidation would produce IQ[4,5-b].

By studying the different proposed reaction pathways it is possible to understand why the different imidazopyridine derivatives are produced to different extents. Thus, the concentration of the reactants and the formation of the final ${ }_{50}$ pyridine ring are likely playing a major role in the amount of the heterocyclic aromatic amine produced. Next two sections will be dedicated to the coordinate contribution of both lipid oxidation and Maillard reaction to the formation of the carbonyl compounds required for producing the imidazopyridine skeleton.

\section{${ }_{5 s} 3$. The Strecker degradation of amino acids and other degradative pathways that produce Strecker aldehydes as a consequence of both Maillard reaction and lipid oxidation}

Strecker degradation is part of the oxidative decarboxylation 60 reactions of amino acids that can be effected by a variety of reagents and reaction conditions. ${ }^{24}$ This reaction is a source of important volatile constituents of food flavours. Thus, in addition to the aldehyde derived from the parent amino acids, usually named Strecker aldehyde, different pyrazines, pyridines, pyrroles, 65 and oxazoles, among other compounds, are produced. ${ }^{25}$

In Maillard chemistry, the term Strecker degradation is usually employed when $\alpha$-dicarbonyl compounds act as oxidizing agents to effect the decarboxylation of the involved amino acid. Many $\alpha$-dicarbonyl compounds are produced in the course of Maillard 70 reaction by carbohydrate dehydration or fragmentation, including 1- or 3-deoxyosones, glyoxal, 2,3-butanedione, and 2oxopropanal. The reaction of phenylacetaldehyde, as a model amino acid, with glyoxal, as a model $\alpha$-dicarbonyl compound, is shown in Scheme 6 .

75 The reaction begins with the formation of the corresponding conjugated imine between the amino group of the amino acid and one of the carbonyl groups of the glyoxal. The formed $\alpha$ iminocarbonyl compound undergoes then a thermally induced, irreversible decarboxylation. The reason for this loss of carbon 80 dioxide can be better understood from the zwitterionic form of the $\alpha$-iminocarbonyl compound. The carbon dioxide loss is facilitated by the formation of an azomethine ylide, which is stabilized by resonance because of its conjugation with the 
<smiles>CC1=CC2C(=Cc3c(nc(N)n3C)NC3C=C(C)C(C(=O)OCc4ccc(C)o4)=CN32)O1</smiles>

Scheme 4 Suggested formation pathway of 2-amino-1,6-dimethylfuro[3,2-e]imidazo[4,5-b]pyridine (IFP)<smiles>O=Cc1ccccc1</smiles><smiles>CN1CC(=O)N=C1N</smiles><smiles>CN1C(N)=NC(=O)C1C(O)c1ccccc1</smiles><smiles>CO</smiles><smiles>CN1C(N)=NC(=O)/C1=C\c1ccccc1</smiles><smiles>Cn1c(N)nc2nc3ccccc3cc21</smiles><smiles>CC(C)C</smiles><smiles>Cn1c(N)nc2c1C=C1C=CC=CC1N2</smiles>

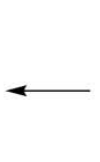<smiles>CN1C(N)=NC(=N)/C1=C\c1ccccc1</smiles>

Scheme 5 Suggested formation pathway of 2-amino-1-methylimidazo[4,5-b]quinoline (IQ[4,5-b])

carbonyl function. Finally, the azomethine ylide undergoes 5 addition of water to produce the Strecker aldehyde (phenylacetaldehyde) and a 2-oxoamino derivative (2aminoacetaldehyde).

$\alpha$-Dicarbonyl compounds are not major lipid oxidation products, although glyoxal and other short-chain $\alpha$-dicarbonyl 10 compounds are known to be produced to a certain extent as a consequence of lipid oxidation. ${ }^{35}$ However, in the course of lipid oxidation, many compounds analogous to $\alpha$-dicarbonyl compounds are produced which are able to degrade amino acids similarly to the $\alpha$-dicarbonyl compounds derived from 15 carbohydrates.

The Strecker degradation of amino acids produced by secondary lipid oxidation products was firstly described in 2004 for the formation of phenylacetaldehyde by phenylalanine degradation in the presence of epoxyalkenals, ${ }^{26}$ and later 20 extended to other lipid-derived reactive carbonyls. ${ }^{36-38}$ Strecker aldehyde formation by lipid oxidation products is believed to be produced analogously to amino acid degradation by $\alpha$-dicarbonyl compounds. Scheme 7 shows the reaction pathway for the degradation of phenylalanine in the presence of 4,525 epoxyalkenals. The reaction begins with the formation of the imine that suffers then the decarboxylation. This loss is facilitated by the extension of the conjugation in the produced azomethine ylide because of the existence of the second oxygenated function. The final addition of water produces the Strecker aldehyde 30 (phenylacetaldehyde) and a hydroxyamino derivative which, for 4,5-epoxyalkenals, evolves to 2-alkypyridines.

This reaction is not exclusive for lipid-derived short chain aldehydes, the corresponding long-chain ketones produced during the lipid oxidation pathway are also able to degrade amino 35 acids. ${ }^{37,39}$ In fact, the ability of aldehydes and ketones for degrading amino acids was similar in most experiments and differences found might be more related to differences in solubility among the different lipid oxidation products than differences in reactivity. ${ }^{40}$ In addition, this reaction has also been ${ }_{40}$ described for lipid hydroperoxides ${ }^{41}$ although a free radical mechanism is likely taking place in this degradation in addition to the contribution of the reactive carbonyls produced by 


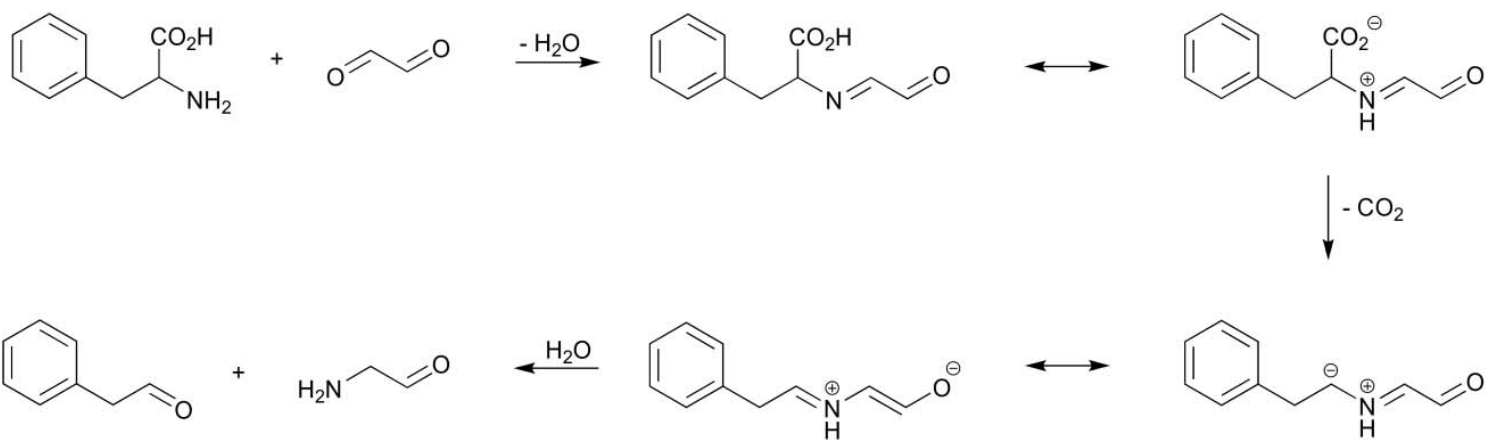

Scheme 6 Strecker degradation of phenylalanine produced by glyoxal

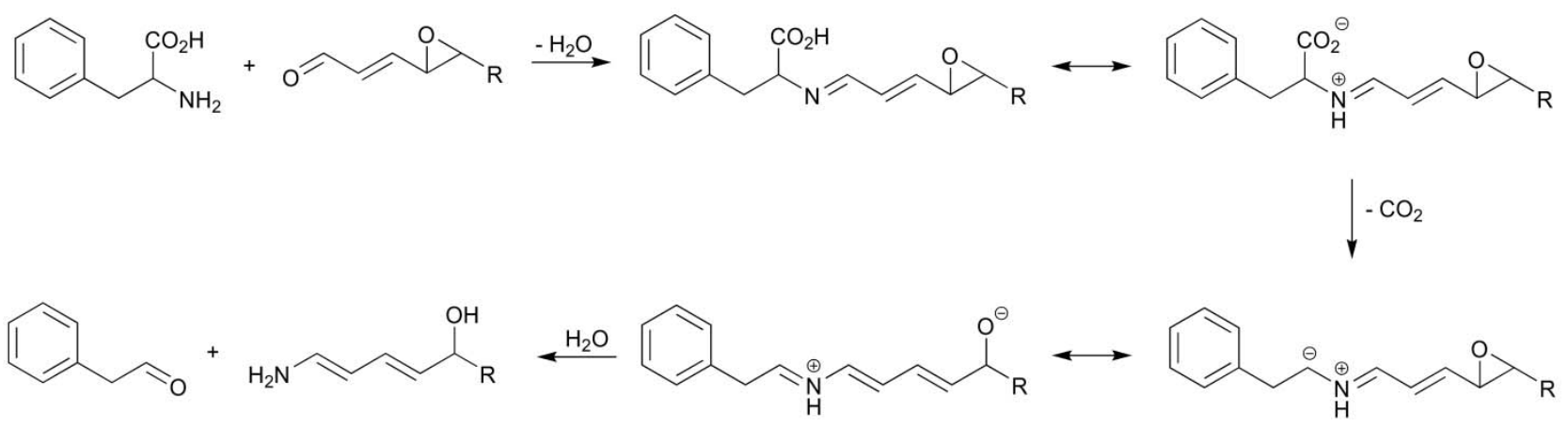

Scheme 7 Strecker degradation of phenylalanine produced by 4,5-epoxy-2-alkenals

hydroperoxide decomposition. ${ }^{40}$

Strecker aldehydes have also been described to be produced by decarboxylation of $\alpha$-oxoacids, ${ }^{42}$ and these last compounds can also be formed by amino acid degradation in the presence of both carbohydrates and oxidized lipids. Thus, for example, Ferreira et al. ${ }^{43}$ found $\alpha$-oxoacids in wines and related them with the 10 generation of aged wine aroma as a consequence of Maillard reaction. A mechanism for $\alpha$-oxoacid formation by isomerisation of the Schiff base formed between the amino acid and glyceraldehydes was suggested by Chu and Yaylayan. ${ }^{44}$ These authors suggested the existence of a transamination. Scheme 8

15 shows a reaction pathway for the formation of phenylpyruvic acid from phenylalanine in the presence of glyoxal. The reaction begins with the formation of the corresponding imine. This compound suffer then an isomerisation that can be seen as a tautomerism because of the existence of the second carbonyl 20 group. This tautomerism may also be favoured because of the extension of the conjugation with the carboxylic group. The hydrolysis of this new imine would produce the $\alpha$-oxoacid.

A similar reaction was previously described for both activated amine and amino acid degradations in the presence of lipid ${ }_{25}$ oxidation products. ${ }^{45,46}$ Scheme 9 shows the reaction pathway of phenylalanine degradation in the presence of 4,5-epoxyalkenals.
As can be observed, the electronic rearrangement is favoured by both the existence of an epoxy group at one end and the conjugation of the carboxylic group produced as a consequence 30 of the isomerisation. This pathway is also valid for amines, although the reaction will be or not produced depending on the electronic effects of the substituents present at the $\alpha$-carbon. Thus, long-chain saturated amines, in which the $\alpha$-carbon is joined to an amino group and an alkyl chain, were converted into 35 carbonyl compounds only to a very low extent. ${ }^{45}$ On the other hand, 2-phenylglycine methyl ester, in which the $\alpha$-carbon is joined to an amino group, an aromatic ring, and a methoxycarbonyl group produced the corresponding carbonyl compound with a reaction yield of about $50 \%$ in the presence of ${ }_{40} 4,5$-epoxyalkenals. ${ }^{45}$

\section{Origin of other aldehydes needed for ring closure in heterocyclic aromatic amine formation having imidazopyridine structure}

The other aldehydes required for ring closure of 45 aminoimidazoazarenes are also produced as both carbohydrate and lipid oxidation products. Thus, the formaldehyde required for 


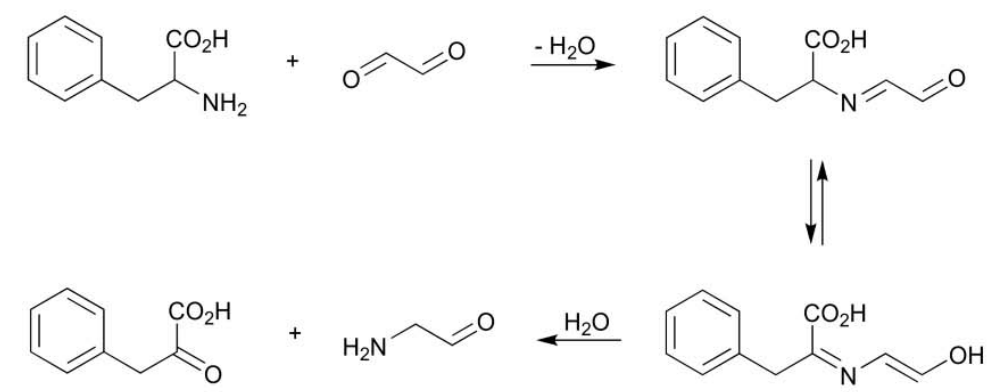

Scheme 8 Formation of phenylpyruvic acid from phenylalanine produced by glyoxal<smiles>NC(Cc1ccccc1)C(=O)O</smiles><smiles>[R]C1OC1/C=C/C=N/C(Cc1ccccc1)C(=O)O</smiles><smiles>[R]C(O)/C=C/C=C/N=C(Cc1ccccc1)C(=O)OC([R])/C=C/C=C/N</smiles>

Scheme 9 Formation of phenylpyruvic acid from phenylalanine produced by 4,5-epoxy-2-alkenals

ring closure in $\mathrm{PhIP}$ has long been known to be a product of ${ }_{5}$ carbohydrate cleavage as a consequence of retroaldol reactions. ${ }^{47}$ In addition, it can be produced by amino acid degradation in the presence of carbohydrates, such as in the Strecker degradation of glycine. ${ }^{48}$ Furthermore, retroaldol reaction of serine has also been shown to produce formaldehyde. ${ }^{49}$

10 Formaldehyde is also commonly produced as a consequence of lipid oxidation. ${ }^{50}$ Recently, Zamora et al. $^{51}$ have shown its formation during thermal degradation of $\alpha, \beta$-unsaturated carbonyls. Formaldehyde might be hypothesised to be produced from these carbonyls analogously to their formation from 15 phenylacetaldehyde discussed above (Scheme 2). The proposed formation mechanism for formaldehyde formation when starting from 2-pentenal is shown in Scheme 10. Upon thermal heating, the $\alpha, \beta$-unsaturated aldehyde might suffer a disproportionation reaction to produce the corresponding acid and alcohol 20 derivatives. The later dehydration of the alcohol, the oxidation of the produced olefin, and, finally, its breakage would be the origin of formaldehyde. In the case of 2-pentenal, 2-butenal (crotonaldehyde) would also be produced in addition to formaldehyde. Crotonaldehyde is a well-known aldehyde ${ }_{25}$ produced in heat-processed edible fats and oils as well as in food mainly from $n 3$ fatty acids. ${ }^{52} n 3$ Fatty acids are also the origin of 2-pentenal, which agrees with the formation of crotonaldehyde from this kind of fatty acids.

In addition to formaldehyde as the second carbonyl compound 30 responsible for PhIP formation, most reactive carbonyl compounds proposed above as responsible for the formation of the different imidazopyridine derivatives are also produced from both carbohydrates and lipids in a coordinate way. Thus, acetaldehyde is formed from both carbohydrates and lipids, 35 among other food components; ${ }^{31}$-methylfurfural is also a byproduct of the Maillard reaction ${ }^{32}$ as well as a product of lipid oxidation $;^{33}$ and benzaldehyde is produced in the degradation of phenylalanine in the presence of both lipids and carbohydrates. ${ }^{34}$ The only exception would be propanal, which is a major lipid 40 oxidation product, but it does not seem to be produced from carbohydrates to a significant extent. ${ }^{30}$ If the proposed pathways for 2-amino-1,6-dimethylimidazo[4,5-b]pyridine (DIMP) and 2amino-1,5,6-trimethylimidazo[4,5-b]pyridine $(1,5,6-\mathrm{TMIP})$ formation in Scheme 3 are correct, the formation of these ${ }_{45}$ heterocyclic aromatic amines should be mainly produced in the presence of lipids.

\section{Inhibition of PhIP formation by phenolic compounds}




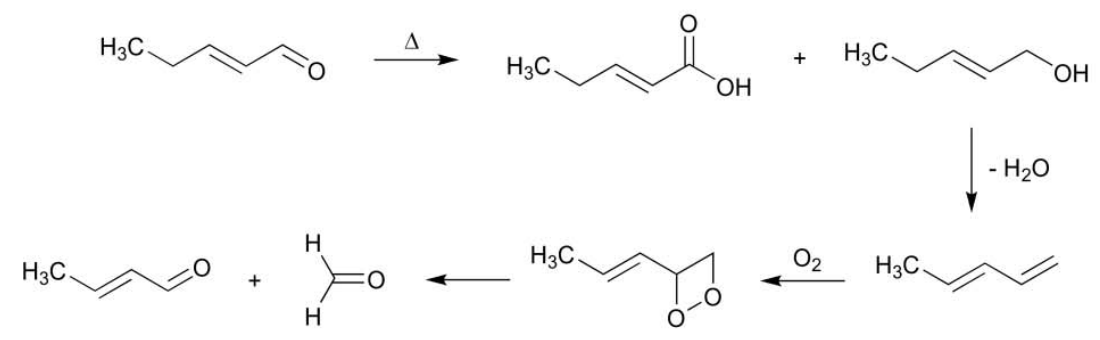

Scheme 10 Formation of formaldehyde by 2-pentenal degradation

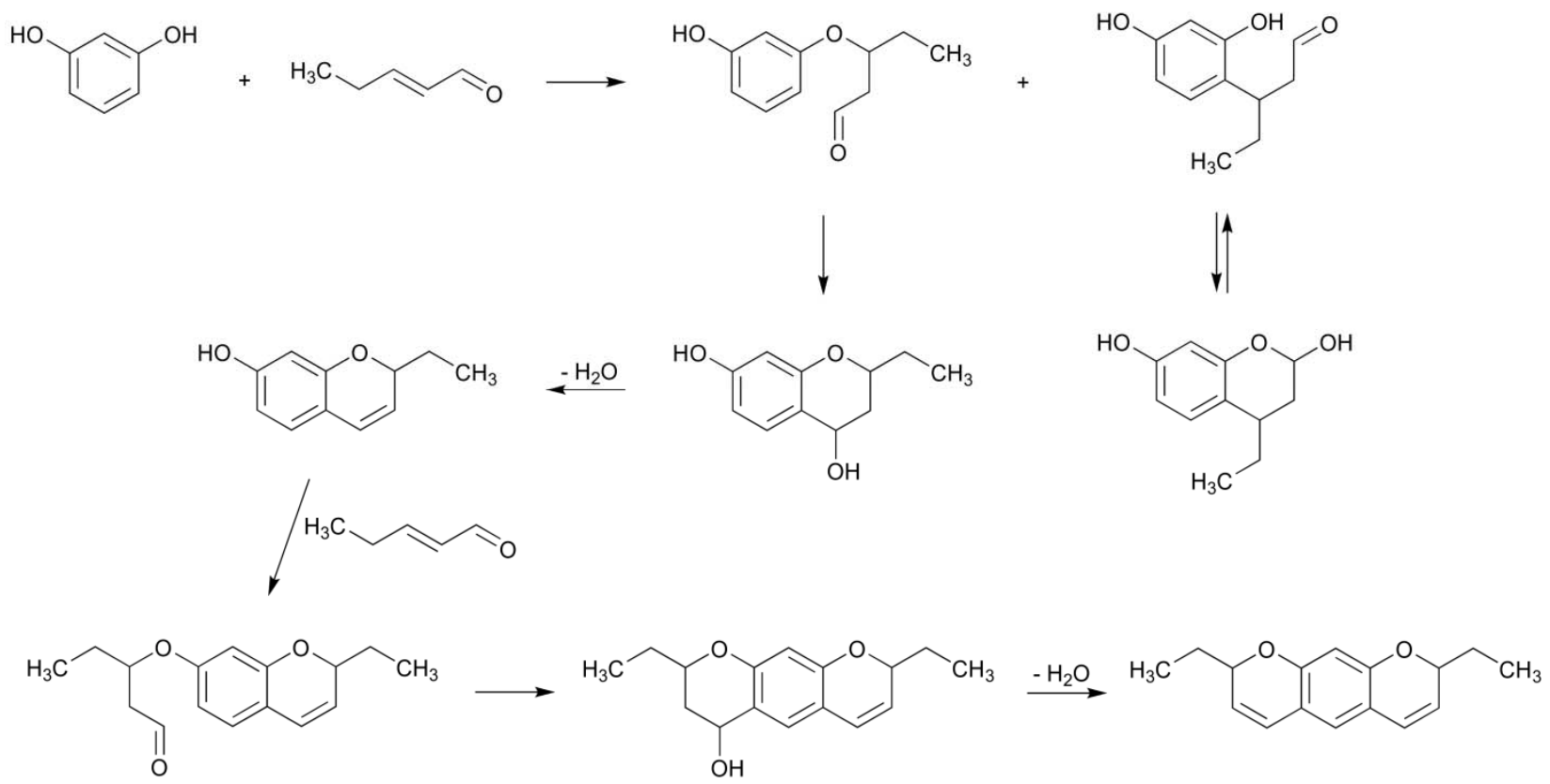

Scheme 11 Reaction of resorcinol with 2-pentenal

Because PhIP is a product of carbonyl chemistry, any compound 5 that can scavenge carbonyl compounds will play a major role in PhIP formation, and this control should be independent of the origin of the carbonyl compound (either carbohydrate or lipid). To this respect, phenolic compounds have been traditionally used to control heterocyclic aromatic amine formation and many 10 authors have shown that the use of phenolic compounds (and plant extracts rich in them) decreases the PhIP formed. ${ }^{53}$ However, the inhibition of PhIP formation was not well correlated with the antioxidant/free radical-scavenging capacity of phenolic compounds, ${ }^{54}$ therefore suggesting the existence of an 15 antioxidant-independent mechanism for PhIP inhibition by phenolic compounds. In fact, this mechanism is related to the ability of phenolic compounds to scavenge reactive carbonyls. ${ }^{55}$ However, not all phenolic compounds exhibited a similar carbonyl scavenging ability.

${ }_{20}$ A recent study by Salazar et al. ${ }^{56}$ has shown that there is a structure/function relationship for the PhIP scavenging ability of phenolic compounds. The obtained results showed that phenols having two hydroxyl groups at meta position of the aromatic ring were the most efficient inhibitors, playing a role in this inhibitory 25 effect the presence of others substituents at the aromatic ring. The positive or negative effect of these other substituents is related to their electronic effects. Thus, the presence of additional hydroxyl and amino groups at the aromatic ring mostly cancelled the carbonyl-scavenging ability of phenolic compounds, which was 30 absent in ortho- and para-dihydroxy derivatives. Furthermore, the presence of several rings with opposite effects in complex phenols produced a reduced inhibitory effect.

All these results are a consequence of the reaction mechanisms involved in phenol/carbonyls reactions. Hidalgo and Zamora 35 recently described the reaction of phenolic compounds with 2alkenals. ${ }^{57}$ The reaction pathway is schematized in Scheme 11 for the reaction between resorcinol and 2-pentenal. As can be 


\section{Cite this: DOI: 10.1039/c0xx00000x}

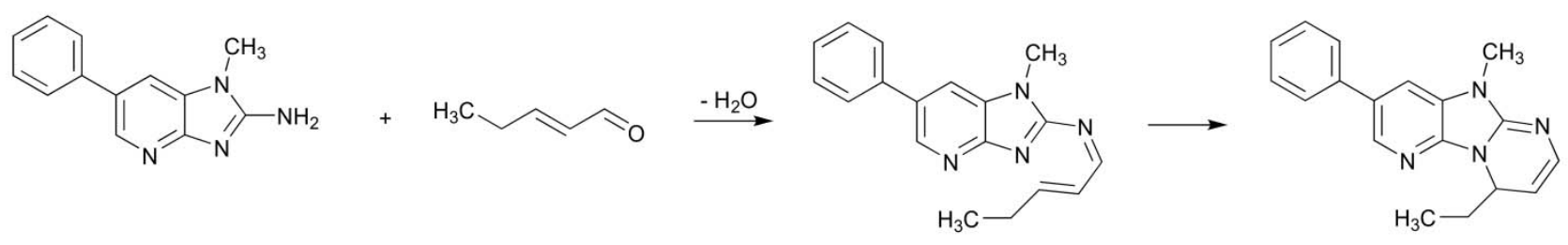

Scheme 12 Reaction of PhIP with 2-pentenal

observed phenolic compounds with two hydroxyl groups at meta positions have two reactive groups toward carbonyl compounds: the hydroxyl groups and the aromatic $\mathrm{CH}$ groups in ortho 5 position to one of the hydroxyl groups and in para position to the second of the hydroxyl groups. The aromatic $\mathrm{CH}$ group in ortho to both hydroxyl groups was less reactive than the other two $\mathrm{CH}$ groups more likely because of steric hindrance. If the reaction is produced by addition of the aromatic $\mathrm{CH}$ group to the carbon10 carbon double bond of the aldehyde, the produced compound is a cyclic hemiacetal with structure of chroman-2,7-diol. If the reaction is produced by addition of the $\mathrm{OH}$ to the carbon-carbon double bond of the aldehyde, the carbonyl of the formed adduct suffer then the addition of the aromatic $\mathrm{CH}$ to produce a cyclic 15 structure which is lately dehydrated to produce a $2 \mathrm{H}$-chromen-7ol. Because this last adduct still has one free $\mathrm{OH}$ and an activated aromatic $\mathrm{CH}$, it can add a second molecule of the aldehyde with the formation of an adduct with the structure of 2,8dihydropyrano[3,2-g]chromene.

20 No all these derivatives exhibited the same stability and chroman-2,7-diols were the main reaction products at high temperature. ${ }^{57}$ For this reason, the adducts formed by the addition of the aromatic $\mathrm{CH}$ group to the carbonyl group in saturated aldehydes have been the reaction products found by different 25 authors. Thus, Cheng et al. ${ }^{58}$ found that epigallocathechin gallate inhibited the formation of $\mathrm{PhIP}$ via scavenging of phenylacetaldehyde, and the reaction took place by addition of the aromatic $\mathrm{CH}$ in ortho to the hydroxyl group in A-ring of the phenol to the carbonyl group. Analogous adducts were found in 30 other reactions involving glyoxal and methylglyoxal. ${ }^{59}$

Therefore, phenolic compounds have been shown to be able to scavenge the carbonyl compounds that are involved in the Strecker degradation of phenylalanine to produce phenylacetaldehyde and also the phenylacetaldehyde once it has 35 been produced. Furthermore, phenols are known to react with formaldehyde. ${ }^{60}$ Consequently, phenolic compounds may be acting at the different steps of $\mathrm{PhIP}$ formation pathway in which carbonyl compounds are involved. The different reactivity of phenolic compounds for the different carbonyl compounds 40 implied at the various steps still remains to be clarified.

\section{PhIP fate in the presence of lipid-derived reactive carbonyls}

Once they have been produced, heterocyclic aromatic amines may be degraded as a function of heating time and temperature. ${ }^{61}$
${ }_{45}$ In addition, Randel et al. ${ }^{62}$ found that different heterocyclic aromatic amines were degraded in oil under storage and frying conditions, a degradation that was parallel to a reduction in their mutagenic potential. Recently, Hidalgo et al. ${ }^{63}$ showed that this degradation is a consequence of the reaction of $\mathrm{PhIP}$ with the ${ }_{50}$ lipid-derived reactive carbonyls produced in the course of lipid oxidation. These authors studied the reaction of $\mathrm{PhIP}$ and its homologous 2-amino-1-methylbenzimidazole with 2-alkenals, 2,4-alkadienals, 4-oxo-2-alkenals, 4,5-epoxy-2-alkenals, and 4hydroxy-2-nonenal and found that those reactions produced the 55 formation of stable heterocyclic structures.

Scheme 12 shows the reaction pathway between PhIP and 2pentenal. The reaction seems to take place firstly with the formation of an imine between the free amino group of $\mathrm{PhIP}$ and the carbonyl group of 2-pentenal. Then, an electronic ${ }_{60}$ rearrangement is produced and a stable adduct having a tricyclic structure is formed. Analogous adducts having all of them similar structures were produced with all assayed reactive carbonyls. However, some carbonyls were more reactive than others and the stability of the produced adducts depended on the other groups ${ }_{65}$ present in the reactive carbonyls in addition to the carbonyl group and the carbon-carbon double bond. Thus, the most reactive carbonyl compounds for this reaction were 4-oxo-2-alkenals and 4,5-epoxy-2-alkenals. On the other hand, the less reactive compounds were 2,4-alkadienals. This reactivity is likely related 70 to the activation of the carbon at $\beta$-position of the carbonyl carbon to participate in the reaction. In addition, the stability of the adduct was determined by the reactivity of the additional group not involved in the reaction that produced the tricyclic adduct.

75 The formation of adducts between PhIP and lipid-derived reactive carbonyls is produced much more easily than the formation of PhIP by reaction of creatinine, phenylalanine and lipid-derived reactive carbonyls because the activation energy $\left(E_{\mathrm{a}}\right)$ of the formation of the tricyclic adduct is much lower than 80 the $E_{\mathrm{a}}$ of PhIP formation $(27.4 \mathrm{~kJ} / \mathrm{mol}$ for PhIP disappearance in the presence of 4-oxo-2-nonenal vs. $80.9 \mathrm{~kJ} / \mathrm{mol}$ for $\mathrm{PhIP}$ formation in the reaction between creatinine, phenylalanine and 4-oxo-2-nonenal). ${ }^{63,64}$ Therefore, once PhIP is produced, lipidderived carbonyls are likely contributing to $\mathrm{PhIP}$ disappearance 85 more than to its formation, at least to a relatively low temperature, which is in agreement with the results of Randel et al. ${ }^{62}$ Furthermore, these results also provide an explanation for the reduction of the mutagenic potential observed in parallel to PhIP disappearance. ${ }^{62}$ Thus, the formed adduct has lost the 
primary amino group of the original $\mathrm{PhIP}$, which seems to be the responsible for its metabolic activation. ${ }^{65}$

Can carbohydrate-derived reactive carbonyls produce an effect similar to that of lipid-derived reactive carbonyls? Although no 5 studies have been carried out in this sense, previous studies have shown that, although monosaccharides increased the formation of heterocyclic aromatic amines when added to a low extent, they exhibited an inbitory effect over amine formation when present to a large excess. ${ }^{66}$ These results seem to be in agreement with a ${ }_{10}$ potential role of carbohydrate-derived reactive carbonyls in PhIP fate, analogously to lipid-derived reactive carbonyls. According to the pathway of Scheme 12, the only requisite for a carbonyl compound to react with PhIP is that it is $\alpha, \beta$-unsaturated. Carbohydrates also produce this kind of carbonyls to some extent 15 during Maillard reaction. ${ }^{67}$ Therefore, carbohydrates might also participate in heterocyclic aromatic amine fate to some extent. Additional studies are needed to confirm this potential aminemitigating power of carbohydrates.

\section{Conclusions}

20 Although PhIP has been traditionally considered to be produced as a by-product of the Maillard reaction between phenylalanine, creati(ni)ne, and carbohydrates, recent evidences suggest that it is a product of carbonyl chemistry in foods, and, as such, other carbonyls can also contribute to its formation. In particular, this 25 review has dealt with the role of lipid-derived carbonyl compounds in PhIP formation and fate. Analogously to carbohydrate-derived carbonyls, lipid-derived carbonyls are able to produce the Strecker degradation of phenylalanine to form phenylacetaldehyde, the key molecule that reacts with creatinine 30 to generate the first intermediate in PhIP formation. Furthermore, lipid-derived carbonyls also produce formaldehyde, the molecule responsible for the ring closure in PhIP. This ability is also shared by carbohydrate-derived reactive carbonyls. Moreover, lipidderived reactive carbonyls are also able to react with PhIP ${ }_{35}$ producing stable adducts in which the free amino group of PhIP has disappeared. This last ability has not been yet investigated for carbohydrate-derived reactive carbonyls, although the decreases observed for PhIP formation in the presence of excess of carbohydrates point out to a scavenging role also for these last 40 reactive carbonyls. All these results, which might also be extended to other aminoimidazoazarenes with the structure of imidazopyridine, point out to a similar role of carbohydrate- and lipid-derived reactive carbonyls that are likely contributing to $\mathrm{PhIP}$ formation and fate in an analogous way, therefore extending

45 the coordinate contribution of both carbohydrates and lipids to food browning ${ }^{14}$ also to the production and elimination of process-related food toxicants.

\section{Acknowledgements}

This study was supported in part by the European Union (FEDER 50 funds) and the Plan Nacional de I + D of the Ministerio de Economía y Competitividad of Spain (project AGL2012-35627).

\section{Notes and references}

${ }^{a}$ Instituto de la Grasa, Consejo Superior de Investigaciones Científicas, Carretera de Utrera km 1, Campus Universitario - Edificio 46, 41013
55 Seville, Spain. Fax:+34 954616 790; Tel: +34 954611 550; E-mail: fhidalgo@ig.csic.es

1 M. van Boekel, V. Fogliano, N. Pellegrini, C. Stanton, G. Scholz, S. Lalljie, V. Somoza, D. Knorr, P. R. Jasti and G. Eisenbrand, Mol. Nutr. Food Res., 2010, 54, 1215.

2 C. J. Seal, A. de Mul, G. Eisenbrand, A. J. Haverkort, K. Franke, S. P. D. Lalljie, H. Mykkänen, E. Reimerdes, G. Scholz, V. Somoza, S. Tuijtelaars, M. van Boekel, J. van Klaveren, S. J. Wilcockson and L. Wilms, Br. J. Nutr., 2008, 99, S1.

653 (a) B. O. Riboldi, A. M. Vinhas and J. D. Moreira, Food Chem., 2014, 157, 310. (b) Y. Xu, B. Cui, R. Ran, Y. Liu, H. P. Chen, G. Y. Kai and J. X. Shi, Food Chem. Toxicol., 2014, 69, 1. (c) B. Matthaus and N. U. Haase, Eur. J. Lipid Sci. Technol., 2014, 116, 675. (d) F. J. van de Brug, N. B. L. Luijckx, H. J. Cnossen and G. F. Houben, 70 Food Control, 2014, 39, 75. (e) P. Pedreschi, M. S. Mariotti and K. Granby, J. Sci. Food Agric., 2014, 94, 9. (f) V. Gokmen, Qual. Assur. Saf. Crop. Foods, 2014, 6, 319. (g) I. S. Arvanitoyannis and N. Dionisopoulou, Crit. Rev. Food Sci. Nutr., 2014, 54, 708.

4 (a) T. Y. Curtis, J. Postles and N. G. Halford, J. Cereal Sci., 59, 382.

75 (b) M. Anese, L. Manzocco, S. Calligaris and M. C. Nicoli, J. Agric. Food Chem., 2013, 61, 10209. (c) M. S. Mariotti, K. Granby, J. Rozowski and F. Pedreschi, Food \& Funct., 2013, 4, 1001. (d) M. Anese and M. Suman, Food Res. Int., 51, 257. (e) R. Seljasen, H. L. Kristensen, C. Lauridsen, G. S. Wyss, U. Kretzschmar, I. BirlouezAragone and J. Kahl, J. Sci. Food Agric., 2013, 93, 2611. (f) S. Moro, J. K. Chipman, J. W. Wegener, C. Hamberger, W. Dekant and A. Mally, Mol. Nutr. Food Res., 2012, 56, 1197.

5 (a) K. Abraham, S. Andres, R. Palavinskas, K. Berg, K. E. Appel and A. Lampen, Mol. Nutr. Food Res., 2011, 55, 1277. (b) Q. Zhu, Z. 85 Sun, Y. Jiang, F. Chen and M. F. Wang, Mol. Nutr. Food Res., 2011, 55, 1375. (c) H.-J. C. Chen, Mol. Nutr. Food Res., 2011, 55, 1391. (d) M. S. Tang, H. T. Wang, Y. Hu, W. S. Chen, M. Akao, Z. H. Feng, and W. W. Hu, Mol. Nutr. Food Res., 2011, 55, 1291. (e) G. Aldini, M. Orioli and M. Carini, Mol. Nutr. Food Res., 2011, 55, 90 1301. (f) R. Y. Shi, T. Rickett and W. J. Sun, Mol. Nutr. Food Res., 2011, 55, 1320. (g) K. Bein and G. D. Leikauf, Mol. Nutr. Food Res., 2011, 55, 1342

6 (a) M. A. Shabbir, A. Raza, F. M. Anjum, M. R. Khan and H. A. R. Suleria, Crit. Rev. Food Sci. Nutr., 2015, 55, 82. (b) U. U. Rahman, 95 A. Sahar, M. I. Khan and M. Nadeem, LWT-Food Sci. Technol., 2014, 59, 229. (c) J. Trafialek and W. Kalanowski, Int. J. Food Sci. Nutr., 2014, 65, 774. (d) M. Friedman, J. Agric. Food Chem., 2014, 62, 6025. (e) K. Sloczynska, B. Powroznik, E. Pekala and A. M. Waszkielewicz, J. Appl. Genet., 2014, 55, 273. (f) D. Behsnilian, P. Butz, R. Greiner and R. Lautenschlaeger, Meat Sci., 2014, 98, 392. (g) Z. Abid, A. J. Cross and R. Sinha, Am. J. Clin. Nutr., 2014, 100, 386S. (h) E. Kim, D. Coelho and F. Blachier, Nutr. Res., 2013, 33, 983.

7 T. Sugimura, K. Wakabayashi, H. Nakagama and M. Nagao, Cancer Sci., 2004, 95, 290-299.

8 (a) M. S. Alaejos, V. Gonzalez and A. M. Alonso, Food Addit. Contam. Part A-Chem., 2008, 25, 2. (b) H. S. Shin and H. S. Shin, Food Sci. Biotechnol., 2003, 12, 588. (c) K. G. Lee and T. Shibamoto, Food Rev. Int., 2002, 18, 151. (d) B. Stavric, Food Chem. Toxicol., 1994, 32, 977.

9 M. S. Alaejos and A. M. Afonso, Compr. Rev. Food Sci. Food Saf., 2011, 10, 52.

10 International Agency for Research on Cancer, IARC Monographs of the Evaluation of the Carcinogenic Risk of Chemicals to Humans, World Health Organization, International Agency for Research on Cancer, Lyon, vol. 56, pp. 163-242. Available at http://monographs.iarc.fr/ENG/Monographs/vol56/ [accessed 06.10.14].

11 National Toxicology Program, in $12^{\text {th }}$ Report on Carcinogens, US 120 Department of Health and Human Services, Public Health Service, National Toxicology Program, pp. 221-224. Available at: http://ntp.niehs.nih.gov/?objectid=03C9AF75-E1BF-FF40DBA9EC0928DF8B15 [accessed 06.10.14].

12 R. Zamora, E. Alcon and F. J. Hidalgo, Food Chem., 2012, 135, 2569.

This journal is (C) The Royal Society of Chemistry [year]

Journal Name, [year], [vol], 00-00 | 11 
13 K. I. Skog, M. A. E. Johansson and M. I. Jagerstad, Food Chem. Toxicol., 1998, 36, 879.

14 R. Zamora and F. J. Hidalgo, Crit. Rev. Food Sci. Nutr., 2005, 45, 49.

15 W. Ni, L. McNaughton, D. M. LeMaster, R. Sinha and R. J. Turesky, J. Agric. Food Chem., 2008, 56, 68.

16 S. Zöchling and M. Murkovic, Food Chem., 2002, 79, 125.

17 K. Puangsombat, P. Gadgil, T. A. Houser, M. C. Hunt and J. S. Smith, Meat Sci., 2011, 88, 227.

18 A. Solyakov and K. Skog, Food Chem. Toxicol., 2002, 40, 1205.

1019 R. Zamora, E. Alcon and F. J. Hidalgo, Food Chem., 2014, 155, 74.

20 K.-W. Cheng, C. C. Wong, C. K. Cho, I. K. Chu, K. H. Sze, C. Lo, F. Chen and M. Wang, Chem. Res. Toxicol., 2008, 21, 2026.

21 J. S. Felton, M. K. Knize, F. T. Hatch, M. J. Tanga and M. E. Colvin, Cancer Lett., 1999, 143, 127.

1522 M. Murkovic, J. Chromatogr. B, 2004, 802, 3.

23 M. Murkovic, H.-J. Weber, S. Geiszler, K. Fröhlich and W. Pfannhauser, Food Chem., 1999, 65, 233.

24 V. A. Yaylayan, Food Sci. Technol. Res., 2003, 1, 1.

25 G. P. Rizzi, Food Rev. Int., 2008, 24, 416.

2026 F. J. Hidalgo and R. Zamora, J. Agric. Food Chem., 2004, 52, 7126.

27 F. J. Hidalgo, E. Alcon and R. Zamora, Food Res. Int., 2013, 54, 1394.

28 G. P. Rizzi, J. Agric. Food Chem., 2006, 54, 1893.

29 (a) M. Sohn and C.-T. Ho, J. Agric. Food Chem., 1995, 43, 3001. (b) V. A. Yaylayan, C. P. Locas, A. Wnorowski and J. O'Brien, J. Agric. Food Chem., 2004, 52, 5569.

30 (a) M. S. Katsuda, D. J. McClements, L. H. S. Miglioranza and E. A. Decker, J. Agric. Food Chem., 2008, 56, 5926. (b) H. Moriya, T. Kuniminato, M. Hosokawa, K. Fukonaga, T. Nishiyama and K. Miyashita, Fish. Sci., 2007, 73, 668. (c) F. Nacka, M. Cansell, P. Meleard and N. Combe, Lipids, 2001, 36, 1313. (d) E. N. Frankel, E. J. Parks, R. Xu, B. O. Schneeman, P. A. Davis and J. B. German, Lipids, 1994, 29, 233.

31 (a) A. Ott, J. E. Germond and A. Chaintreau, J. Agric. Food Chem., 2000, 48, 1512. (b) S.-Q. Liu and G. J. Pilone, J. Food Sci. Technol., 2000, 35, 49. (c) T. A. Miyake and T. Shibamoto, J. Agric. Food Chem., 1998, 46, 3694. (d) T. Miyake and T. Shibamoto, J. Agric. Food Chem., 1995, 43, 1669.

32 L. A. Ameur, B. Rega, P. Giampaoli, G. Trystram and I. BirlouezAragon, Food Chem., 2008, 111, 758.

33 G. Takeoka, C. Perrino, Jr., and R. Buttery, J. Agric. Food Chem., 1996, 44, 654

34 (a) Y. Q. Wen, F. He, B. Q. Zhu, Y. B. Lan, Q. H. Pan, C. Y. Li, M. J. Reeves and J. Wang, Food Chem., 2014, 152, 29. (b) L. Xiao, J.

45 Lee, G. Zhang, S. E. Ebeler, N. Wickramasinghe, J. Seiber and A. E. Mitchel, Food Chem., 2014, 151, 31. (c) W. Wu, N. P. Tao and S. Q. Gu, Eur. Food Res. Technol., 2014, 238, 237. (d) S. G. Cho and S. J. Kays, Food Res. Int., 2013, 54, 1463.

35 (a) L. P. Han, L. Li, B. Li, D. Zhao, Y. T. Li, Z. B. Xu and G. Q. Liu, Food Res. Int., 2013, 51, 836. (b) Y. P. Jiang, M. Hengel, C. P. Pan, J. N. Seiber and T. Shibamoto, J. Agric. Food Chem., 2013, 61, 1067. (c) A. N. Onyango, Chem. Phys. Lipids, 2012, 165, 777.

36 F. J. Hidalgo, E. Gallardo and R. Zamora, J. Agric. Food Chem., 2005, 53, 10254

5537 R. Zamora, E. Gallardo and F. J. Hidalgo, J. Agric. Food Chem., 2007, 55, 1308.

38 R. Zamora, E. Alcon and F. J. Hidalgo, J. Agric. Food Chem., 2013, 61, 10231.

39 R. Zamora, E. Gallardo, J. L. Navarro and F. J. Hidalgo, J. Agric. Food Chem., 2005, 53, 4583

40 F. J. Hidalgo and R. Zamora, Crit. Rev. Food Sci. Nutr., in press, DOI: $10.1080 / 10408398.2012 .761173$

41 R. Zamora, E. Gallardo and F. J. Hidalgo, J. Agric. Food Chem. 2008, 56, 7970 .

6542 F. L. Chu and V. A. Yaylayan, J. Agric. Food Chem., 2008, 56, 10697.

43 A. C. D. S. Ferreira, S. Reis, C. Rodrigues, C. Oliveira and P. G. D. Pinho, J. Food Sci., 2007, 72, S314.

44 F. L. Chu and V. A. Yaylayan, Ann. N. Y. Acad. Sci., 2008, 1126, 30.

7045 R. Zamora, E. Gallardo and Francisco J. Hidalgo, J. Agric. Food Chem., 2006, 54, 2398
46 R. Zamora, J. L. Navarro, E. Gallardo and F. J. Hidalgo, J. Agric. Food Chem., 2006, 54, 6101.

47 F. Ledl and E. Schleicher, Angew. Chem. Int. Ed. Engl., 1990, 29, 565

48 I. Blank and L. B. Fay, J. Agric. Food Chem., 1996, 44, 531.

49 V. A. Yaylayan, A. Keyhani and A. Wnorowski, J. Agric. Food Chem., 2000, 48, 636.

50 (a) S. Matthew, C. Grey, K. Rumpunen and P. Adlercreutz, Food Chem., 2011, 126, 1399. (b) T. C. Huang, C. T. Ho and H. Y. Fu, J. Agric. Food Chem., 2004, 52, 2924.

51 R. Zamora, J. L.Navarro, I. Aguilar and F. J. Hidalgo, Food Chem., $2015, \mathbf{1 7 4}, 89$.

52 (a) M. Granvog1, J. Agric. Food Chem., 2014, 62, 1272. (b) G. Luna, M. T. Morales and R. Aparicio, J. Agric. Food Chem., 2006, 54, 4790. (c) M. Qian and G. Reineccius, J. Dairy Sci., 2002, 85, 1362. (d) W. E. Neff and E. Selke, J. Am. Oil Chem. Soc., 1993, 70, 157.

53 (a) M. Murkovic, S. Steinberger and W. Pfannhauser, Z. Lebensm. Unters. Forschung, 1998, 207, 477. (b) I. Quelhas, C. Petisca, O.

Viegas, A. Melo, O. Pinho and I. M. P. L. V. O. Ferreira, Food Chem., 2010, 122, 98. (c) B. Janoszka, Food Chem., 2010, 120, 463. (d) M. Gibis and J. Weiss, Food Chem., 2012, 134, 766.

54 (a) J. Damasius, P. R. Venskutonis, R. Ferracane and V. Fogliano, Food Chem., 2011, 126, 149. (b) K. W. Cheng, F. Chen and M. Wang, Mol. Nutr. Food Res., 2007, 51, 969.

55 (a) V. N. Totlani and D. G. Peterson, J. Agric. Food Chem., 2005, 53, 4130. (b) X. Peng, K.-W. Cheng, J. Ma, B. Chen, C. T. Ho, C. Lo, F. Chen and M. Wang, J. Agric. Food Chem., 2008, 56, 1907. (c) C.-Y. Lo, W.-T. Hsiao and X.-Y. Chen, J. Food Sci., 2011, 76, H90.

10056 R. Salazar, G. Arámbula-Villa, F. J. Hidalgo and R. Zamora, Food Chem., 2014, 151, 480.

57 F. J. Hidalgo and R. Zamora, Food Chem., 2014, 160, 118.

58 K.-W. Cheng, C. C. Wong, J. Chao, C. Lo, F. Chen, I. K. Chu, C.-M. Che, C.-T. Ho and M. Wang, Mol. Nutr. Food Res., 2009, 53, 716.

10559 (a) V. M. Totlani and D. G. Peterson, J. Agric. Food Chem., 2006 54, 7311. (b) C.-Y. Lo, S. Li, D. Tan, M.-H. Pan, S. Sang and C.-T. Ho, Mol. Nutr. Food Res., 2006, 50, 1118. (c) H. Liu, H. Liu, W. Wang, C. Khoo, J. Taylor and L. Gu, Food Funct., 2011, 2, 475. (d) S. Kokkinidou and D. G. Peterson, Food Funct., 2013, 4, 1093.

11060 G. Casiraghi, G. Casnati, A. Pochini, G. Puglia, R. Ungaro and G. Sartori, Synthesis, 1981, 143

61 C. P. Chiu and B. H. Chen, Food Chem., 2000, 68, 267.

62 G. Randel, M. Balzer, S. Grupe, S. Drusch, B. Kaina, K.-L. Platt and K. Schwarz, Food Chem. Toxicol., 2007, 45, 2245.

11563 F. J. Hidalgo, E. Alcon and R. Zamora, J. Agric. Food Chem., 2014 62, 12045

64 R. Zamora, E. Alcon and F. J. Hidalgo, Food Chem., 2013, 138, 180.

65 C. Cheung, X. Ma, K. W. Krausz, S. Kimura, L. Feigenbaum, T. P. Dalton, D. W. Nebert, J. R. Idle and F. J. Gonzalez, Chem. Res. Toxicol., 2005, 18, 1471

66 (a) K. Skog, M. Jägerstad and L. Reuterswärd, Food Chem. Toxicol., 1992, 30, 681. (b) K. Skog, Food Chem. Toxicol., 1993, 31, 665. (c) M. Bordas, E. Moyano, L. Puignou and M. T. Galceran, J. Chromatogr. B, 2004, 802, 11.

${ }_{25} 67$ S. Estendorfer, F. Ledl and T. Severin, Angew. Chem. Int. Ed. Engl., 1990, 29, 536. 